\title{
DEXMEDETOMIDINE AS AN ADJUVANT FOR INTRAVENOUS REGIONAL ANESTHESIA IN UPPER LIMB SURGERIES
}

\author{
By
Mostafa A. Abo El-Enin, Ahmed M. El-Garhy, Ahmed M. Abd El-Geleal, and Hamza M. Elewa \\ Department of Anesthesiology and Intensive Care, Faculty of Medicine, Al-Azhar \\ University
}

Corresponding author: Hamza M. Elewa; E-mail: wezza.elzamalkawy@gmail.com

Mobile: 01092309118

\begin{abstract}
Background: Intravenous regional anesthesia (IVRA) is an anesthetic technique for surgical procedures on the body's extremities where a local anesthetic is injected intravenously.

Objective: To compare between the intravenous regional anesthesias using lidocaine only and lidocaine plus dexmedetomidine as regards onset of sensory and motor block, intraoperative hemodynamic effects, onset of tourniquet pain and postoperative pain assessment.
\end{abstract}

Patients and Methods: This study included 60 patients of both sex admitted for forearm surgeries carried out at Al-Azhar University Hospitals (El-Hussein and Bab El-Sha'arya). They were randomly allocated into two equal groups. Group I: lidocaine group received only lidocaine. Group II: received lidocaine plus dexmedetomidine. The following parameters were assessed between the two groups: onset of sensory and motor block, hemodynamics (MAP, HR and SpO2), onset of tourniquet pain and postoperative pain scoring.

Results: There is a statistically significant increase of the mean of Group II compared to Group I according to onset of sensory block ( $\mathrm{min})$. Also, there was a statistically significant increase mean of Group II compared to Group I according to onset of motor block (min).

Conclusion: Dexmedetomidine as adjuvant to lidocaine in intravenous regional anesthesia produces early onset of sensory and motor block, delayed onset of tourniquet pain, lower postoperative visual analogue score, longer duration of postoperative analgesia.

Key words: Dexmedetomidine, intravenous regional anesthesia, upper limb, surgery

\section{INTRODUCTION}

Intravenous regional anesthesia (IVRA) was first described by German surgeon, August Bier in 1908. Bier's block involves the intravenous administration of local anesthetic into a tourniquet occluded limb (Vanzundert et al., 2013).

IVRA has multiple advantages, including ease of administration, rate of recovery, rapid onset, muscular relaxation, and controllable extent of anesthesia. It is an excellent technique for short $(<90$ minutes) open surgical procedures (Miller et al., 2014).

Intravenous regional anesthesia of the upper limb remains popular because it is reliable, cost effective, safe, and simple to administer. It is a widely accepted technique well suited for brief minor 


\section{MOSTAFA A. ABO EL-ENIN et al.,}

surgeries such as excision of wrist or hand ganglion, carpal tunnel release, Dupuytren contractures and reduction of fractures (Kumar et al., 2012).

Disadvantages of (IVRA) include incomplete muscle relaxation and lack of postoperative pain relief after tourniquet deflation, because of the rapid washout of anesthetic solution in general circulation Guay (2009).

Intravenous regional anesthesia provides safe and effective anesthesia for hand surgery of one- hour duration or less. In an attempt to improve the postoperative analgesia, various adjuvants such as opioids and alpha 2 agonist like dexmedetomidine have been added to the local anesthetic solution with varying degrees of efficacy (Brummett and Williams, 2011).

Different agents have been used as additive to local anesthetic for IVRA including opioids, non-steroidal antiinflammatory drugs (NSAID), muscle relaxants, ketamine and dexmedetomidine (Nilekani et al., 2016).

Dexmedetomidine, a potent alpha $(\alpha)$ 2- adrenoceptor agonist, has been shown to decrease anesthetic requirements by up to $90 \%$ and to induce analgesia. The addition of dexmedetomidine to lidocaine for IVRA improves quality of anesthesia and postoperative analgesia without causing side effects (Kumar et al., 2012).

The aim of the present work was to evaluate the efficacy of dexmedetomidine as an adjuvant for intravenous regional anesthesia in upper limp surgeries as regard onset of sensory and motor blocks as primary outcome, and tourniquet pain, postoperative pain score and hemodynamics as secondary outcome.

\section{PATIENTS AND METHODS}

After obtaining approval from the ethical committee, patients of ASA grade I \& II age between 20-60 years who came for forearm and hand surgeries lasting for less than 60 minutes were included in this study. The present study was conducted in Al-Azhar University Hospitals on 60 patients of both sexes after signing written informed consents from June 2019 to Nov 2019.

The present study was designed as a prospective double blind randomized control study. Randomization was performed using a closed envelope method. The lidocaine in the study was $2 \%$ preservative free in all groups. In all groups $0.9 \% \mathrm{NaCl}$ was added to make up a total volume of $40 \mathrm{ml}$.

Patients were classified into 2 equal groups as follows: Group I received IVRA using $40 \mathrm{ml}$ of lidocaine $(0.5 \%)$ as a control group, and Group II received IVRA using $40 \mathrm{ml}$ of lidocaine $(0.5 \%)$ plus dexmedetomidine $(0.5 \mathrm{mcg} / \mathrm{kg})$.

Operations were forearm and hand surgeries such as distal radius fracture (DR), plate ulna (PU) for ulnar bone fracture, metacarpal bone fracture (MCF), and trigger finger (TF), simple ganglion resection (SG) and carpal tunnel syndrome (CTS).

Patients with history of allergic reaction to lidocaine, and dexmedetomidine, history of chronic pain or regular medication with analgesics, history of opioid dependence, drug or alcohol abuse, psychiatric disorders and 
neurological diseases, significant cardiovascular disease, chronic nitroglycerine consumption and peripheral vascular disease, sickle cell disease were excluded from the study.

Preoperative assessment was
performed focusing on routine
preoperative assessment to fulfill patient criteria for the study by full history taking, physical examination including chest and heart examination. Study protocol was explained to the patients taking their consent. Explanation of Visual Analog Scale (VAS) scoring system for all patients. Routine investigations: $\mathrm{CBC}$, ALT, AST, serum albumin and bilirubin level, serum urea and creatinine level and coagulation profile.

\section{Methods:}

- Premedication for all groups consisted of IV midazolam $0.15 \mathrm{mg} / \mathrm{kg}$.

- Double pneumatic tourniquet, the pressure gauge should be checked for leaks before the procedure.

- Esmarch bandage for exsanguination.

- Two IV catheters, size $20 \mathrm{G}$ and $22 \mathrm{G}$, Infusion set, $5 \mathrm{ml}$ and $20 \mathrm{ml}$ syringes.

- Drugs: Lidocaine (Lidocaine injection $2 \%, 20 \mathrm{ml}$ preservative free, ALDebiky pharma,

Egypt),Dexmedetomidine

(Dexmedetomidine hydrochloride) injection, $200 \mu \mathrm{g} / 2 \mathrm{ml}$ preservative free, Abbott laboratory, USA). Normal saline was added to make up a total volume of $40 \mathrm{ml}$.

- Equipments and drugs for general anesthesia and resuscitation: Oxygen supply, airway, laryngoscope with different size blades, endotracheal tubes of different sizes, suction apparatus, thiopental, succinylcholine, atropine, epinephrine and DC shock.

- After application of monitors (ECG, SPO2, and NIBP) to the patient lying in supine position; a cannula, 20G size, was placed in the non-operative hand for crystalloid infusion and emergency drugs. Another cannula $22 \mathrm{G}$ size was inserted in a dorsal vein of the operative hand.

- A double pneumatic tourniquet was then placed around the upper arm of the operative limb, over a pad of cotton. The arm was elevated for 2 min then exsanguinated with an Esmarch bandage. In case of a painful limb, where exsanguination of the limb could not be carried out, limb elevation was done for two min. then the limb was exsanguinated below the level of fracture.

- The proximal cuff was inflated to100 $\mathrm{mm} \mathrm{Hg}$ above the patient's systolic pressure. Circulatory isolation of the arm was verified by inspection, absence of radial pulse and loss of pulse oximetry tracing in the ipsilateral index finger. Then $40 \mathrm{ml}$ of lidocaine $0.5 \%$ in Group I, lidocaine with dexmetomedine $(0.5 \mu / \mathrm{kg})$ in Group II was injected slowly within 60 seconds.

- When anesthesia was established confirmed by complete sensory and motor block, the distal cuff of the tourniquet was inflated to $250 \mathrm{mmHg}$ then the proximal one was deflated. The least time before tourniquet release was 30 minutes and the maximum time could be allowed was 90 minutes. 
- Boluses of $1 \mathrm{mcg} / \mathrm{kg}$ fentanyl were provided for tourniquet pain treatment when required (when VAS was $>3$ ).

- Intraoperative hypotension (systolic blood pressure $<90 \mathrm{mmHg}$ ) was treated with intravenous $5 \mathrm{mg}$ ephedrine; intraoperative bradycardia (HR <60 beats/min) was treated with intravenous $0.5 \mathrm{mg}$ atropine; nausea and vomiting was treated with $10 \mathrm{mg}$ of intravenous metoclopramide; and hypoxemia (decrease in oxygen saturation $<90 \%$ ) was treated with an oxygen face mask.

- A patient who suffered failure of the block due to uncontrollable tourniquet pain was received general anesthesia and replaced by another patient.

Postoperatively, patient with VAS >3 was given diclofenac $75 \mathrm{mg}$.

\section{Measurements and parameters of the study:}

\section{Onset of sensory block:}

Sensory block onset time (the time elapsed from injection of the drug to the sensory block achieved in all dermatomes).

Tested by pin prick test performed with a 22- gauge short beveled needle every 30 sec. in the middle of dermatomal distribution of each nerve, ulnar nerve (fingers 4 and 5), radial nerve (dorsal surface of fingers 1,2, and 3), and median nerve (medial surface of fingers 1,2 , and 3).

\section{Onset of motor block:}

Motor block onset time is the time elapsed from injection of the local anesthetics up to complete motor block.
Motor block was determined by thumb abduction (radial nerve), thumb adduction (ulnar nerve), thumb opposition (median nerve), and flexion of elbow (musculocutaneous nerve).

\section{Secondary outcome:}

1. Hemodynamic parameters: Heart rate(HR), mean arterial blood pressure (MAP) and peripheral oxygen saturation (SpO2)were recorded before anesthesia as a baseline; intraoperative; at 5, 10,15, 20, 30 ,and 40 minutes after proximal tourniquet deflation, then at the end of surgery. The data in each group were compared with the baseline data at the same group.

\section{Onset of tourniquet pain: Using} visual analogue scale (VAS), from 0 to 10 scores where 0 defines no pain and 10 defines the maximum intolerable pain. The VAS was a $10-\mathrm{cm}$ horizontal line labeled "no pain" at one end and "worst pain imaginable" on the other end. The patient was asked to mark on this line where the intensity of the pain lies. The distance from "no pain" to the patient's mark numerically quantitates the pain..

3. Postoperative pain score: Using VAS monitoring at 1, 2, 3, 4, 5, 6 hrs after distal tourniquet deflation.

\section{Statistical analysis:}

Recorded data were analyzed using the statistical package for social sciences, version 20.0 (SPSS Inc., Chicago, Illinois, USA). Quantitative data were expressed as mean \pm standard deviation (SD) or range. Qualitative data were expressed as frequency and percentage.

The following tests were done: Independent- samples t-test of 
significance was used for normally distributed parametric data. MannWhitney test was used for non-parametric or abnormally distributed data. Chi-square (x2) test of significance was used in order to compare proportions between qualitative parameters. The confidence interval was set to $95 \%$ and the margin of error accepted was set to $5 \%$. So, the pvalue was considered significant as the following: Probability (P-value); P-value $<0.05$ was considered significant. P-value $<0.001$ was considered as highly significant. P-value $>0.05$ was considered insignificant.

\section{RESULTS}

No statistically significant difference between Group I and Group II according to demographic data, while there were statistically significant increases of the mean of Group II compared to Group I according to sensory onset (min). Also,there was a statistically significant increase mean of Group II compared to Group I according to motor onset (Table 1).

Table (1): Demographic data, sensory and motor onset in both groups

\begin{tabular}{|c|c|c|c|}
\hline $\begin{array}{ll}\text { Parameters } & \text { Groups } \\
\end{array}$ & Group I $(n=30)$ & $\begin{array}{c}\text { Group II } \\
(\mathbf{n}=\mathbf{3 0})\end{array}$ & P-value \\
\hline $\begin{array}{l}\text { Age (years) } \\
\text { Range } \\
\text { Mean } \pm \text { SD }\end{array}$ & $\begin{array}{c}20-60 \\
39.52 \pm 11.44\end{array}$ & $\begin{array}{c}20-60 \\
39.73 \pm 9.98\end{array}$ & $>0.05$ \\
\hline $\begin{array}{l}\text { Sex } \\
\text { Male } \\
\text { Female }\end{array}$ & $\begin{array}{l}20(66.7 \%) \\
10(33.3 \%)\end{array}$ & $\begin{array}{l}17(56.7 \%) \\
13(43.3 \%)\end{array}$ & $>0.05$ \\
\hline Weight(kg) & $81.12 \pm 7.18$ & $79.35 \pm 5.51$ & $>0.05$ \\
\hline Height $(\mathrm{cm})$ & $172.33 \pm 4.26$ & $173.16 \pm 3.02$ & $>0.05$ \\
\hline $\begin{array}{l}\text { ASA } \\
\text { I } \\
\text { II }\end{array}$ & $\begin{array}{l}18(60.0 \%) \\
12(40.0 \%)\end{array}$ & $\begin{array}{l}21(70.0 \%) \\
9(30.0 \%)\end{array}$ & $>0.05$ \\
\hline $\begin{array}{l}\text { Duration of Surgery (min) } \\
\text { Range } \\
\text { Mean } \pm \text { SD }\end{array}$ & $\begin{array}{c}30-45 \\
35.5 \pm 9.2\end{array}$ & $\begin{array}{c}30-45 \\
33.8 \pm 9.7\end{array}$ & $>0.05$ \\
\hline Sensory onset (min) & $6.28 \pm 0.47$ & $5.82 \pm 0.47$ & $<0.05$ \\
\hline Motor onset (min) & $9.17 \pm 1.42$ & $7.83 \pm 0.38$ & $<0.05$ \\
\hline
\end{tabular}

There was no statistically significant difference between groups according to intraoperative mean arterial blood pressure, heart rate or arterial oxygen saturation (Table 2). 
Table (2): Comparison between Group I and Group II according to intraoperative mean arterial blood pressure ( $\mathrm{mmHg}$ ), heart rate (beat/min.) and arterial oxygen saturation (\% $\mathrm{O} 2$ sat.)

\begin{tabular}{|c|c|c|c|c|}
\hline Parameters & Time & $\begin{array}{c}\text { Group I } \\
(\mathbf{n}=\mathbf{3 0})\end{array}$ & $\begin{array}{c}\text { Group II } \\
(\mathbf{n}=\mathbf{3 0})\end{array}$ & p-value \\
\hline \multirow{8}{*}{ 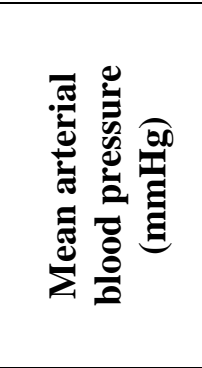 } & Base & $100.32 \pm 2.17$ & $100.22 \pm 2.43$ & $>0.05$ \\
\hline & $5 \mathrm{~min}$ & $98.58 \pm 1.33$ & $97.97 \pm 0.96$ & $>0.05$ \\
\hline & 10min & $97.98 \pm 1.33$ & $97.61 \pm 0.88$ & $>0.05$ \\
\hline & 15min & $99.04 \pm 1.28$ & $98.79 \pm 2.61$ & $>0.05$ \\
\hline & 20min & $99.15 \pm 1.31$ & $98.38 \pm 2.35$ & $>0.05$ \\
\hline & 30min & $100.22 \pm 1.51$ & $99.45 \pm 1.97$ & $>0.05$ \\
\hline & 40min & $101.13 \pm 1.59$ & $100.67 \pm 2.60$ & $>0.05$ \\
\hline & End & $101.34 \pm 1.37$ & $100.22 \pm 2.95$ & $>0.05$ \\
\hline \multirow{8}{*}{ 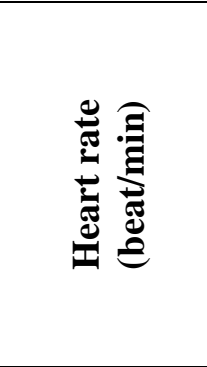 } & Baseline & $81.35 \pm 2.15$ & $80.95 \pm 3.38$ & $>0.05$ \\
\hline & 5min. & $79.00 \pm 2.07$ & $78.49 \pm 2.30$ & $>0.05$ \\
\hline & 10min. & $77.72 \pm 3.79$ & $77.42 \pm 2.66$ & $>0.05$ \\
\hline & $15 \mathrm{~min}$. & $80.43 \pm 3.49$ & $78.39 \pm 2.44$ & $>0.05$ \\
\hline & 20min. & $80.38 \pm 2.75$ & $79.05 \pm 3.11$ & $>0.05$ \\
\hline & 30min. & $82.82 \pm 3.14$ & $82.06 \pm 3.24$ & $>0.05$ \\
\hline & 40min. & $84.76 \pm 2.76$ & $83.54 \pm 1.71$ & $>0.05$ \\
\hline & End & $85.02 \pm 2.37$ & $84.76 \pm 2.47$ & $>0.05$ \\
\hline \multirow{8}{*}{ 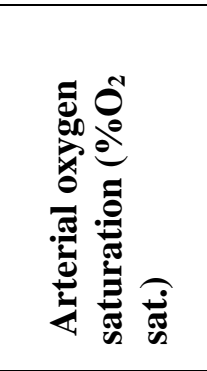 } & Base & $98.40 \pm 0.47$ & $98.20 \pm 0.50$ & $>0.05$ \\
\hline & $5 \mathrm{~min}$ & $98.50 \pm 0.44$ & $98.20 \pm 0.36$ & $>0.05$ \\
\hline & 10min & $98.40 \pm 0.47$ & $98.40 \pm 0.47$ & $>0.05$ \\
\hline & $15 \mathrm{~min}$ & $98.40 \pm 0.47$ & $98.25 \pm 0.36$ & $>0.05$ \\
\hline & 20min & $98.35 \pm 0.71$ & $98.25 \pm 0.58$ & $>0.05$ \\
\hline & 30min & $98.15 \pm 0.51$ & $98.30 \pm 0.61$ & $>0.05$ \\
\hline & 40min & $98.10 \pm 0.32$ & $98.10 \pm 0.39$ & $>0.05$ \\
\hline & End & $98.25 \pm 0.48$ & $98.10 \pm 0.22$ & $>0.05$ \\
\hline
\end{tabular}

There was a statistically significant increase mean of Group II compared to
Group I according to onset of tourniquet pain (Table 3).

Table (3): Comparison between Group I and Group II according to onset of tourniquet pain (min)

\begin{tabular}{|l|c|c|c|}
\hline Group & $\begin{array}{c}\text { Group I } \\
(\mathbf{n = 3 0})\end{array}$ & $\begin{array}{c}\text { Group II } \\
(\mathbf{n = 3 0})\end{array}$ & $\begin{array}{c}\text { p- } \\
\text { value }\end{array}$ \\
\hline Onset of tourniquet pain (min) & $26.85 \pm 1.87$ & $42.76 \pm 2.72$ & $<0.001$ \\
\hline
\end{tabular}

There was a statistically significant increase mean of Group I compared to
Group II according to postoperative of VAS score from at $1 \mathrm{hr}$ to $6 \mathrm{hrs}$ (Table 4). 
Table (4): Comparison between Group I and Group II according to VAS score.

\begin{tabular}{|l|c|c|c|}
\hline Time & $\begin{array}{c}\text { Group I } \\
(\mathbf{n = 3 0})\end{array}$ & $\begin{array}{c}\text { Group II } \\
(\mathbf{n = 3 0})\end{array}$ & p-value \\
\hline $\mathbf{1 h r}$ & $3.93 \pm 0.37$ & $1.63 \pm 0.51$ & $<0.001$ \\
\hline $\mathbf{2 h r s}$ & $3.16 \pm 0.31$ & $2.19 \pm 0.49$ & $<0.001$ \\
\hline $\mathbf{3} \mathbf{~ h r s}$ & $3.57 \pm 0.52$ & $2.35 \pm 0.74$ & $<0.001$ \\
\hline $\mathbf{4} \mathbf{h r s}$ & $3.52 \pm 0.52$ & $1.94 \pm 1.22$ & $<0.001$ \\
\hline $\mathbf{5 h r s}$ & $3.01 \pm 0.22$ & $1.53 \pm 1.94$ & $<0.001$ \\
\hline $\mathbf{6} \mathbf{h r s}$ & $2.70 \pm 0.49$ & $2.24 \pm 0.42$ & $<0.001$ \\
\hline
\end{tabular}

\section{DISCUSSION}

Intravenous regional anesthesia offers numerous advantages over conventional general anesthesia (GA), including faster recovery time, fewer side effects, no need for airway manipulation during surgery, and a dramatic reduction in post-surgical pain. IVRA reduced nursing time demand in the PACU and early hospital discharge when compared with GA and brachial plexus block but it often didn't not provide effective postoperative analgesia. Patients who receive regional anesthesia instead of general anesthesia can also avoid Postoperative nausea, vomiting and recover quickly after surgery (Kumar et al., 2012).

In the present study, statistical analysis of the demographic data of the patients and procedural characters did not show any significant differences between the three groups, as regards age, sex, weight and height of the patients, as well as type and duration of surgery. Onset time of sensory and motor block was significantly different between Group I and Group II.As regard intraoperative hemodynamics; there was no statistical significance between Group I and II. On the other hand, there was a statistical significance between the two groups as regard onset of tourniquet pain, and there was a significant decrease of pain score in Group II when compared with Group I at the 1 st 6 hours postoperatively.

In accordance to the present study, $E l$ Shalakany and Salah (2015), compared between adding dexemeditomidine to lidocaine in IVRA and noticed that there was decrease pain scores (VAS) intraoperative and postoperatively, delays the onset of tourniquet pain. They noticed that there was no statistically significant difference between the 2 groups as regard intraoperative hemodynamics changes: Dexmedetomidine did not affect the onset of sensory or motor block but instead prolonged sensory and motor block duration which is not inaccordance to the present study.

In accordance to the present study, Subramanya et al. (2017) evaluated the effect of dexmedetomidine $(0.5 \mathrm{mcg} / \mathrm{kg})$ as an adjuvant for lignocaine $(0.5 \%)$ in intravenous regional anesthesia, noticed that there was earlier onset of sensory and motor block in Group II when compared to Group I, delayed onset of tourniquet pain in group II, when compared with Group I, and decrease pain scores (VAS) intraoperatively and postoperatively.

Kol et al. (2009) reported that the addition of dexmetomedine to lidocaine delayed onset time of tourniquet pain in 
IVRA through improving quality of block as regards onset and offset.

In contrast to the present study Esmaoglu et al. (2005) observed that addition of dexmedetomidine to lignocaine in IVRA anesthesia has no effect on the sensory and motor block onset and regression times as they used a higher dose of dexmedetomidine $(1 \mu \mathrm{g} / \mathrm{kg})$ compared with our study.

\section{CONCLUSION}

Dexmedetomidine as adjuvant to lidocaine in intravenous regional anesthesia produced early onset of sensory and motor block, delayed onset of tourniquet pain, lower postoperative visual analogue score and longer duration of postoperative analgesia.

\section{REFERENCES}

1. Brummett, C. M. and Williams, B. A. (2011): Additives to local anesthetics for peripheral nerve blockade. International Anesthesiology Clinics, 49(4), 104-116.

2. El-Shalakany, N. A. and Salah, A. M. (2015): Anesthetic and analgesic efficacy, hemodynamic changes, and sedation following addition of dexmedetomidine to lignocaine in intravenous regional anesthesia for minor hand surgery. Ain-Shams Journal of Anaesthesiology, 8(4), 670- 677.

3. Esmaoglu, A. L. İ. Y. E., Mizrak, A., Akin, A., Turk, Y., and Boyaci, A. (2005): Addition of dexmedetomidine to lidocaine for intravenous regional anesthesia. European journal of Anesthesiology, 22(6), 447-451.

4. Guay, J. (2009): Adverse events associated with intravenous regional anesthesia (Bier block): a systematic review of complications. Journal of Clinical Anesthesia, 21(8): 585594.

5. Kol, I. O., Ozturk, H., Kaygusuz, K., Gursoy, S., Comert, B. \& Mimaroglu, C. (2009): Addition of dexmedetomidine or lornoxicam to prilocaine in Intravenous regional anaesthesia for hand or forearm surgery. Clinical drug investigation, 29(2), 121-129.

6. Kumar A; Sharma D and Datta B (2012): Addition of dexmedetomidine to lignocaine in intravenous regional anesthesia, A randomized controlled study. J Anesthesiology Clinical Pharmacology, 28:501-4.

7. Miller RD, Bhana N, Goa KL and McClellan KJ (2014): Dexmedetomidine pharmacology. Intravenous anesthetics. Miller's Anesthesia 30:854-857.

8. Nilekani, E., MENEzES, Y., and D'souza, S. A. (2016): A Study on the Efficacy of the Addition of Low Dose Dexmedetomidine as an Adjuvant to Lignocaine in Intravenous Regional Anaesthesia (IVRA). Journal of clinical and diagnostic research: JCDR, 10(10), UC01- UC05.

9. Subramanya V; Kapinigowda S; Math A and Chennaiah V (2017): Dexmedetomidine as an Adjuvant for Intravenous Regional Anesthesia in Upper Limb Surgeries. Anesth Essays Res., 11(3): 661-664.

10. Vanzundert A; Helmstadter A and Goerige M (2013): Centennial of intravenous regional anesthesia, Bier block, The Nw York School of regional anesthesia. Regional Anesthesia and Pain Medicine, 33483-489. 


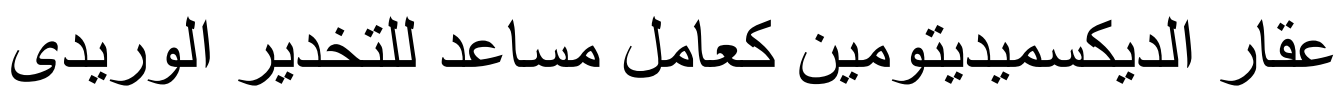

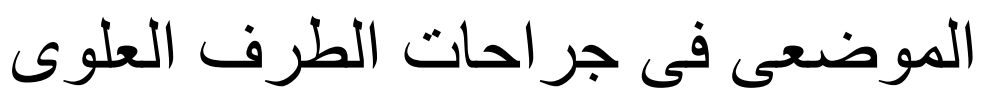

مصطفى عبد الحميد أبو العينين، أحمد محد الجارحى، أحمد محمد عبد الجليل، حمزة محمد عليوه

قسم التخدير والرعاية المركزة، كلية الطب، جامعة/الازهر

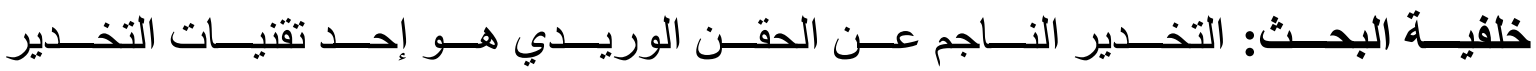

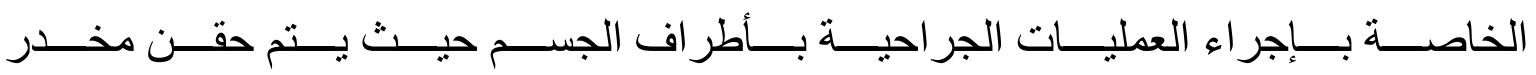

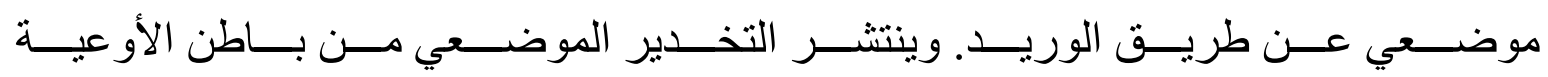

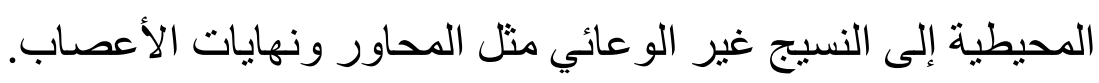

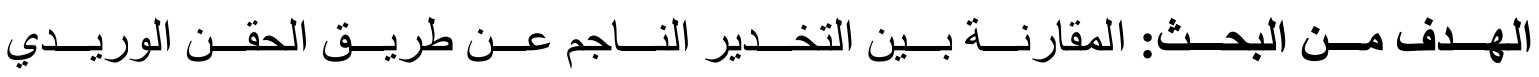

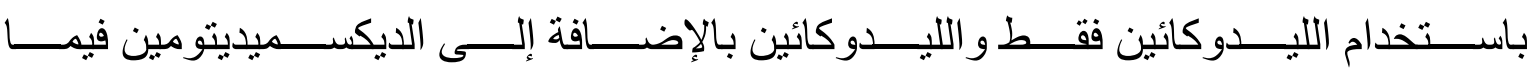

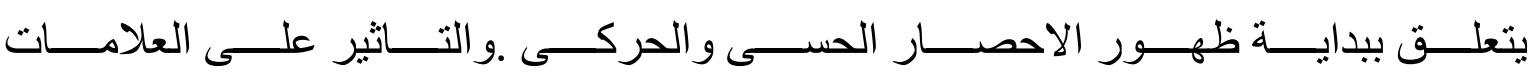

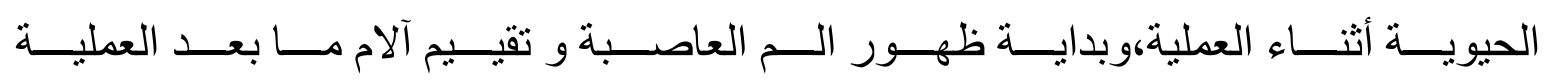
الجر احية.

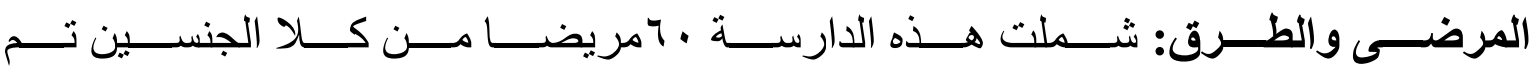

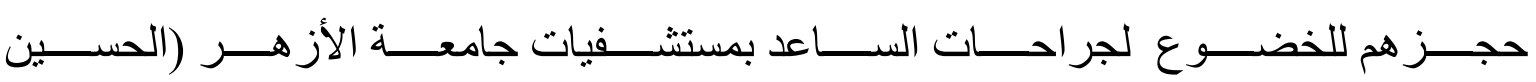

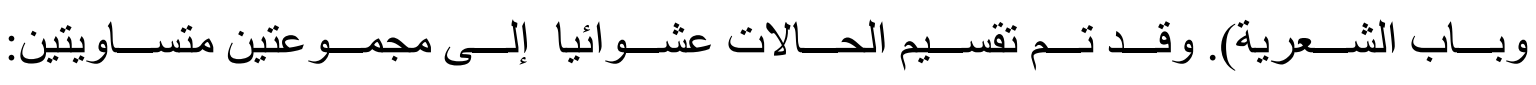

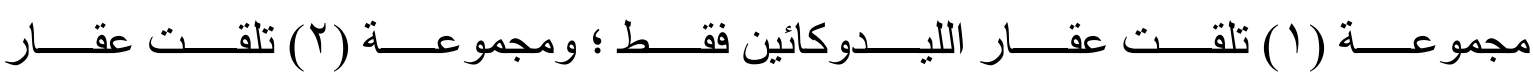
الليدوكائين بالإضافة إلى الديكسميديتو ميدين.

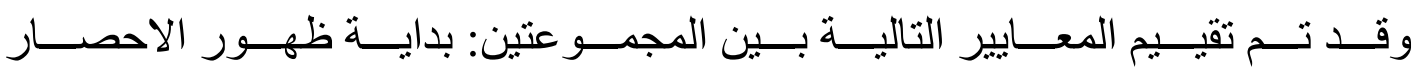

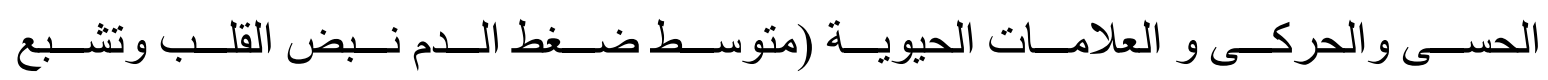

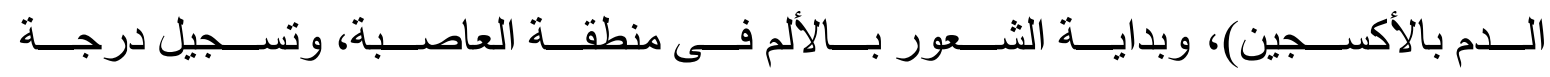
الألم بعد العملية الجر احية. 


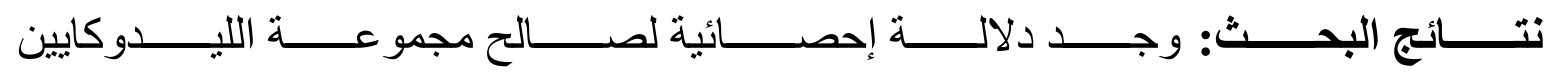

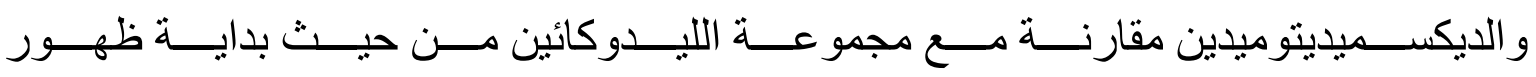
الاحصار الحسى، وبداية ظهور الاحصار الحركى.

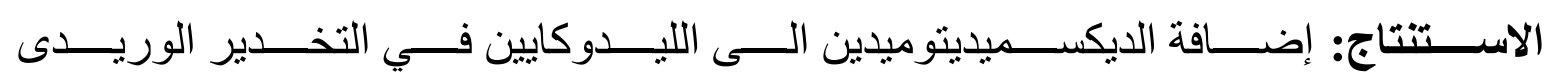

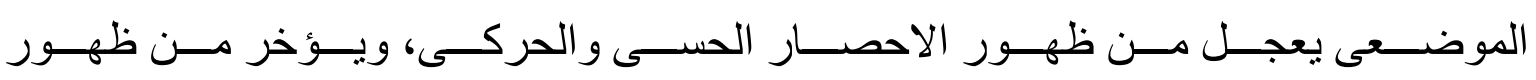
ألم عاصبة، و إنخفاض درجة الالم بعد العملية الجر احية. 